\title{
Delivery Of Curcumin Nanoliposomes Using Surface Modified With CDI33 Aptamers For Prostate
} Cancer

This article was published in the following Dove Press journal: Drug Design, Development and Therapy

\author{
Qi Mal,* \\ Wei Qian ${ }^{2, *}$ \\ Wei Tao ${ }^{2}$ \\ Yanling Zhou ${ }^{3}$ \\ Boxin Xue ${ }^{2}$ \\ 'Department of Ultrasound, The Second \\ Affiliated Hospital of Soochow University, \\ Suzhou, People's Republic of China; \\ ${ }^{2}$ Department of Urology, The Second \\ Affiliated Hospital of Soochow University, \\ Suzhou, People's Republic of China; \\ ${ }^{3}$ Department of Operation, The Second \\ Affiliated Hospital of Soochow University, \\ Suzhou, People's Republic of China \\ *These authors contributed equally to \\ this work
}

Correspondence: Wei Tao

Department of Urology, The Second

Affiliated Hospital of Soochow University,

No. 1055 Sanxiang Road, Gusu District,

Suzhou City, Jiangsu Province, People's

Republic of China

$\mathrm{Tel} / \mathrm{Fax}+86$ 05/2-67784837

Email tw27024@I63.com

Yanling Zhou

Department of Operation, The Second

Affiliated Hospital of Soochow University,

No. 1055 Sanxiang Road, Gusu District,

Suzhou City, Jiangsu Province, People's

Republic of China

Email sdfeyzyl@I63.com
Aim: The aim of this study was to characterize curcumin (CUR)-loaded CD133 aptamer A15 liposomes for their antitumor activity in vitro and in vivo.

Methods: The modified CUR liposomes were prepared by the thin-film hydration technique. Results: The particles showed spherical shape under electron microscopy with sizes $<100$ $\mathrm{nm}$. Initial drug burst release was observed within $2 \mathrm{hrs}$ and then the drug was continuously released over 48 hrs. No aggregation or precipitation of liposomes was observed during storage for 3 months. In vitro results showed that blank LPs had lower cellular cytotoxicity. Both liposomes of CUR (with or without A15 modified) exhibited a similar trend of cellular cytotoxicity at the same concentration. With the extension of incubation time, A15-CUR LPs showed a greater inhibitory effect on cells. Cell internalization in DU145 cells was higher for A15-CUR LPs than others. An in vivo study using DU145 prostate carcinoma bearing mice showed that A15-CUR LPs reduced tumor growth more than other forms of CUR.

Conclusion: These results indicate that A15 modified CUR liposomes are a promising candidate for antitumor drug delivery.

Keywords: CD133 aptamers, curcumin, prostate cancer, liposomes, cell viability, cellular internalization, in vivo evaluation

\section{Introduction}

Prostate cancer is the most common cancer in Chinese men and the second leading cause of death. The annual incidence of prostate cancer in China has been on the rise, with 1,500,000 new cases predicted for 2016. ${ }^{1}$ Advanced prostate cancer is treated with anti-androgens therapy, but after 2 to 3 years of treatment, the tumor usually becomes hormone-resistant and no longer responds to conventional chemotherapy. Traditional chemotherapy leads to nontarget effects where anticancer drugs cause damage to healthy and fast split cells, so patients usually undergo normal organ toxicity. ${ }^{2}$ As a result, many prostate cancer patients need to seek alternative therapies. ${ }^{3,4}$ In fact, most of the major medical centers are now combining their traditional therapies with some form of alternative and complementary drugs, the most popular of which is the use of nutritional modification as well as herbal and other micronutrients. ${ }^{5,6}$

Epidemiological reports show that natural polyphenols used in daily diets can reduce the risk and incidence of various cancers. ${ }^{7,8}$ These compounds are beneficial to overall health and longevity. The use of natural anticancer compounds is very suitable for prostate cancer because of the disease's high incidence rate and long 
latency. ${ }^{9}$ Of many natural anticancer drugs, curcumin (CUR) is a favorable phytochemical, showing a significant potential for the treatment of prostate cancer. ${ }^{10}$ CUR has been used for hundreds of years in traditional medicine in India and China. ${ }^{11}$ It is yellow polyphenol in chemistry, diallyl methane extracted from turmeric rhizomes (Curcuma longa). It has low intrinsic toxicity and a wide range of pharmacological functions, including antitumor, anti-amyloid, antioxidant and anti-inflammatory effects. Previous studies have shown that free CUR can induce cell cycle arrest and/or apoptosis, and inhibit the activation of nuclear factor kappa B (NF-kB) in different tumor cell lines. ${ }^{12,13}$ CUR was associated with the regression of precancerous lesions in bladder, soft palate, gastrointestinal tract, cervix and skin, and with treatment responses in established malignancy. ${ }^{14,15}$ The only factor limiting the use of free CUR in cancer treatment is its poor solubility in water, which also limits its oral bioavailability.

Prostate cancer stem cells (CSCs) are considered an important factor in tumorigenesis, metastasis, proliferation, and resistance to radio and chemotherapy. ${ }^{16}$ CSCs enter asymmetric cell division and produce a daughter cell to become a committed progenitor cell. As a result, hierarchies of actively proliferating, as well as progressively differentiating, cancer cells are formed and lead to cell heterogeneity in human cancers. ${ }^{17}$

CD133 is a membrane glycoprotein with an N-terminal extracellular domain, five transmembrane loops with two large extracellular loops containing eight putative N-linked glycosylation sites, and a cytoplasmic tail. CD133 expression in adult human prostate has been documented to mark normal prostate epithelial stem cells and rare malignant tumor stem/initiating cells. Functional studies have demonstrated that human prostate cancer cell lines do contain a rare population $(\sim 5.0 \%)$ of $\mathrm{CD} 133+$ cells which bear the defining characteristics of tumor stem/initiating cells including low incidence, self-renewability, unlimited proliferative capacity, and ability to give rise to phenotypically different progenies. Our previous studies showed that when CD133+ prostate CSCs constituted a complex and organized structure, cell signal transduction would be different in their surrounding tissues. ${ }^{18,19}$ CD44+ is a member of the cell adhesion protein family and the expression of several CD44 proteins has been related to the invasive stage of various types of human cancers (21). One obvious function of CD44 family members is selective splicing.
Over the past few decades, different strategies, such as liposomes, solid dispersions, complexes, emulsions, micelles, nanogels, and microspheres have been used to overcome poor absorption and other limitations of CUR. The ligand-receptor binding strategy is the classic method for targeting drug delivery. ${ }^{20}$ Aptamer oligonucleotides are ideal target ligands because of their low immunogenicity, low molecular weight, and easy production. ${ }^{21}$ The aptamer A15 has been proved to be a promising ligand for targeting CD44+/CD133+ cells. ${ }^{22,23}$

In this study, we formulated a delivery system where CUR was encapsulated in aptamer A15 modified liposomes by the thin-film hydration technique. The modified CUR liposomes were then characterized for drug loading and encapsulation efficiency, particle size, and surface morphology. Furthermore, the release characteristics, cell uptake, and the effect on cell viability in prostate cancer cell lines of CRU liposomes in vitro were evaluated.

\section{Materials And Methods}

\section{Materials}

CUR was purchased from Puripharm Co., Ltd. (Huzhou, China). The primers and thiolated CD133 aptamer A15 with a sequence of 5'-SH-CCCUCCUACAUAGGG-3' were bought from Ruibo Co., Ltd. (Guangzhou, China). Egg phosphatidylcholine (EPC), DSPE-PEG2000. (1,2distearoyl-sn-glycero-3-phosphoethanolamine-N-[maleimide(polyethylene glycol)-2000]) and cholesterol (CHOL) were obtained from Sinopharm Chemical Reagent (Shanghai, China). The DU145 human prostate cancer cell line was supplied by American Type Culture Collection and was grown in monolayer culture in Dulbecco's modified Eagle's medium-F12 supplemented with $10 \%$ heat-inactivated fetal calf serum, $100 \mathrm{U} / \mathrm{mL}$ penicillin, and $100 \mu \mathrm{g} / \mathrm{mL}$ streptomycin. Methanol, ethanol, ammonium acetate, and ethyl acetate were purchased from Suzhou Chemical Reagent Factory (Suzhou, China) and were of at least analytical grade. Watsons' water was used in all experiments.

\section{Preparation Of Aptamer AI5 Modified CUR Liposomes}

Aptamer A15 modified CUR liposomes (A15-CUR LPs) were prepared using the thin-film dispersion method. In brief, CUR, EPC, CHOL, and DSPE-PEG2000-MAL (weighted $4,25,6.5$, and $1.5 \mathrm{mg}$, respectively) were dissolved in $5 \mathrm{~mL}$ of chloroform to form a mixed solution; 
then the organic solvent was removed under reduced pressure at $36-38^{\circ} \mathrm{C}$ by rotary evaporation to form a thin film on the inner walls of the flask. Vacuum was applied for 1 $\mathrm{hr}$ to ensure that all solvent traces are completely removed.

Glucose and mannitol (1:1, w/w) were dissolved in PBS $(\mathrm{pH}=7.4)$. The lipid film was then hydrated with $5 \mathrm{~mL}$ of PBS $(\mathrm{pH}=7.4)$ at $55^{\circ} \mathrm{C}$ by rotation $(180 \mathrm{rpm} \times 0.5 \mathrm{hr})$ to form CUR-LPs. The targeted modified CUR LPs with Aptamer A15 were fabricated by conjugating aptamers to LPs by thiol-maleimide reaction. ${ }^{24,25}$ Briefly, CUR LPs were prepared as described earlier, and then the CUR LPs suspension was incubated with Aptamer A15 $(1 \% \mathrm{~m} / \mathrm{m})$ for $8 \mathrm{hrs}$ under stirring. After ultrafiltration with PBS, the aptamers modified CUR liposomes (A15-CUR LPs) were resuspended in PBS for use. Then, the liposomes were freeze-dried for $72 \mathrm{hrs}$.

\section{Characterization Of AI5-CUR LPs}

Characterization of the LPs was needed to ascertain their reproducibility in terms of in vitro and in vivo performances. In order to determine the optimal formulation parameters relative to the formulation of the A15-CUR LPs, drug-loading (DL\%), encapsulation ratio (ER\%), particle size, and surface morphology of the LPs were measured. DL\% and ER\% were calculated as described earlier. ${ }^{26}$ Firstly, CUR was extracted from LPs $(20 \mathrm{mg})$ with $2 \mathrm{~mL} \mathrm{5 \%}$ glacial acetic acid and acetonitrile at a ratio of 55 to $45 \mathrm{v} / \mathrm{v}$, and then the extracted solution was properly diluted prior to HPLC analysis.

The content of CUR in LPs was determined by the HPLC method. DL\% and ER\% were calculated according to Equations (1) and (2):

$$
\begin{gathered}
D L \%=W_{M} /\left(W_{P}+W_{M}\right) \times 100 \% \\
E R \%=W_{M} / W_{F} \times 100 \%
\end{gathered}
$$

where $W_{\mathrm{P}}$ is the weight of the initial feeding polymer, $W_{\mathrm{M}}$ is the weight of drug incorporated in LPs, and $W_{\mathrm{F}}$ is the weight of initial feeding drug.

Particle size analysis of A15-CUR LPs was carried out using dynamic light scattering (Nicomp ${ }^{\text {TM }}$ 380ZLS, Particle Sizing Systems, Santa Barbara, CA, USA). The freeze-dried LPs were dispersed in aqueous solution for 2 mins by ultrasonic bath before the particle size was determined. The surface morphology of LPs was studied by transmission electron microscopy (TEM). A small amount of lyophilized solution LPs $(1 \mathrm{mg} / \mathrm{mL})$ was placed on a TEM grid surface with filter paper (Whatman No. 1). A drop of $1 \%$ uranyl acetate was added to the carbon-coated grid surface. After incubation for $1 \mathrm{~min}$, the excess liquid was removed and the mesh surface was air-dried at room temperature. It was then loaded into the transmission electron microscope (JEM-1200 EX, Japan).

\section{In Vitro Release}

A15-CUR LPs (containing $10 \mathrm{mg}$ CUR) were added into $2 \mathrm{~mL}$ of release buffer in dialysis bags $(\mathrm{Mol} \approx 10,000)$, and then placed in a tube containing $50 \mathrm{~mL}$ of phosphate buffer with a $\mathrm{pH}$ value of 7.4 (containing $2 \%$ ethanol as cosolvent). All the samples were under the sink condition and kept in a constantly shaking bath at $100 \mathrm{rpm}$ at $37^{\circ} \mathrm{C}$. At designated time intervals $(0.5,1,2,4,8,12,16,24$, 32 , and $48 \mathrm{hrs}$ ), $2 \mathrm{~mL}$ of dialysate was taken for analysis and replaced by $2 \mathrm{~mL}$ of fresh medium. The concentration of CUR in release medium was determined by HPLC after filtration and proper dilution. At the same time, the release of CUR solution and unmodified LPs $(2 \mathrm{~mL}$, $5 \mathrm{mg} / \mathrm{mL}$ ) was monitored as a control. The accumulative release was analyzed, and the results were shown as mean $\pm \operatorname{SD}(n=3)$.

\section{Stability}

According to the guidelines provided by the International Conference on Harmonisation, experiments on the stability of CUR LPs and A15-CUR LPs were carried out at a temperature of $25^{\circ} \mathrm{C} \pm 2{ }^{\circ} \mathrm{C}$ and a relative humidity of $60 \% \pm 5 \%$ for 1-3 months. DL\%, ER\%, and particle size of the stored samples were determined.

\section{Hemolysis Testing}

This method of safe drug carriers has been reported. ${ }^{27}$ The hemolysis effect of free CUR, CUR LPs, and A15CUR LPs in the blood of New Zealand white rabbits was studied. Blood samples $(10 \mathrm{~mL})$ were collected in heparinized test tubes and, after saline $(10 \mathrm{~mL})$ was added, vortexed for $1 \mathrm{~min}$. The mixture was then centrifuged at $1500 \mathrm{rpm}$ for $15 \mathrm{mins}$. The collected red blood cells were washed with three times of normal saline $(10 \mathrm{~mL})$ and centrifugated repeatedly until the supernatant was no longer red. ${ }^{28,29}$ Erythrocyte pellets $(2 \mathrm{~mL})$ were transferred to saline $(98 \mathrm{~mL})$ to prepare a $2 \%$ erythrocyte standard suspension.

Free CUR, CUR LPs, and A15-CUR LPs were dissolved in physiologic saline at a concentration of $5 \mathrm{mg} / \mathrm{mL}$. After blending, all the tubes were incubated at $37^{\circ} \mathrm{C}$. After $1 \mathrm{hr}$, the samples were centrifuged at $3000 \mathrm{rpm}$ for 5 mins. The 
absorbance (A) of the supernatant was determined at $545 \mathrm{~nm}$ by UV visible spectrophotometry. A total of $0.5 \mathrm{~mL} \mathrm{RBC}$ suspension with $2 \mathrm{~mL}$ of normal saline was used as the negative control $(0 \%$ lysis), while water was used as the positive control ( $100 \%$ lysis).

The positive absorbance value should be $0.8 \pm 0.3$, while the negative less than 0.03 . The hemolytic rates of the samples were calculated as follows:

Hemolytic rate $(\%)=\left[\left(A_{t}-A_{n c}\right) /\left(A_{p c}-A_{n c}\right)\right] \times 100 \%$

where $A_{t}$ represents the absorbance value of the test sample, and $A_{n c}$ and $A_{p c}$, respectively, represent the absorption value of negative and positive control.

\section{Cell Viability}

The in vitro anticancer efficacy of CUR formulations was measured using a Cell Counting Kit-8 (CCK8, Dojindo Molecular Technologies). DU145 cells were seeded in 96well plates $\left(1 \times 10^{5}\right.$ cells $\left./ \mathrm{mL}\right)$ and maintained in Dulbecco's Modified Eagle Medium (DMEM) with 10\% fetal bovine serum (FBS) at $37^{\circ} \mathrm{C}$ and $5 \% \mathrm{CO}_{2}$. The cells were incubated for $48 \mathrm{hrs}$ with 5 different concentrations of CUR dissolved in dimethyl sulfoxide (DMSO, $0.1 \% \mathrm{v} / \mathrm{v}$ ) or blank LPs, CUR LPs, and A15-CUR LPs $(0.1,0.5,2.5$, 5.0, $20 \mathrm{mM}$ ). The CCK8 assay was performed according to the manufacturer's instructions.

\section{Cellular Internalization}

The cellular internalization of free CUR, CUR LPs, and A15-CUR LPs was visualized by confocal microscopy using coumarin-6 as a fluorescent probe. DU145 human prostate cancer cells were grown in DMEM medium supplemented with $10 \%$ (v/v) FBS and 5\% antibiotics. DU145 cells were inoculated in a cell culture dish at $1 \times 10^{7}$ cells per dish for initial density. Cells were then incubated with coumarin-6-adsorbed free CUR, CUR LPs, and A15-CUR LPs (equivalent to $0.1 \mu \mathrm{g} / \mathrm{mL}$ of coumarin-6) for $2 \mathrm{hrs}$ at $37^{\circ} \mathrm{C} \pm 0.5^{\circ} \mathrm{C}$.

Subsequently, the cells were washed with PBS several times and fixed with $4 \%$ paraformaldehyde for 10 mins before observed under the confocal microscopy. For the quantitative estimation of CUR uptake, the density of cells inoculated on 24 -well plates was $3 \times 10^{4}$. When they reached $70-80 \%$ confluence, cells were incubated with coumarin-6-adsorbed free CUR, CUR LPs, and A15CUR LPs (equivalent to $0.1 \mu \mathrm{g} / \mathrm{mL}$ of coumarin-6). After $2 \mathrm{hrs}$ of culturing, cells were washed several times with cold PBS and then dissolved by addition of Triton X-100 $(0.1 \%)$. Fluorescence intensities were measured by a multimode microplate reader at an excitation wavelength of $440 \mathrm{~nm}$ and an emission wavelength of $520 \mathrm{~nm}$.

Flow cytometry assays for the CD133+ cells were performed as previously described. ${ }^{30}$ In brief, following their respective treatments, the DU145 cells were collected and rinsed with PBS. The number of dissociated cells was counted and $1 \times 10^{7}$ cells were subsequently transferred to $100 \mu \mathrm{L}$ buffer containing phycoerythrin (PE)-conjugated CD133/2 antibody (Miltenyi Biotec Inc., Auburn, CA, USA) for 30 mins and protected from light. The cells were then washed and analyzed using a flow cytometer (BD FACSCalibur; BD Biosciences, Franklin Lakes, NJ, USA).

\section{Tumor Targeting}

The in vivo tumor targeting ability of A15-CUR LPs was evaluated by non-invasive optical imaging systems. Tumor-bearing mice models were built according to the previous report. Briefly, $1 \times 10^{7}$ DU145 cells were suspended in $200 \mu \mathrm{L}$ DMEM medium and injected into the left hindlimb flank of mice. DiD (NIRF dye, $50 \mathrm{nM}$ ) were co-loaded into A15-CUR LPs as described earlier. When tumor volume reached $\sim 100-150 \mathrm{~mm}^{3}$, DiD-CUR, DiDCUR LPs and DiD-A15-CUR LPs in $100 \mu \mathrm{L}$ PBS were injected intravenously via the tail vein into tumor-bearing mice. At different time points ( 6 and $12 \mathrm{hrs}$ ), mice were anesthetized by intraperitoneal injection of pentobarbital (35 $\mathrm{mg} / \mathrm{kg}$ ) and scanned using the imaging system IS4000MM (Kodak) with an excitation bandpass filter at $625 \mathrm{~nm}$ and an emission at $700 \mathrm{~nm}$. Exposure time was 30 s per image.

\section{In Vivo Evaluation}

In this study, a DU145 xenograft mouse model was established by subcutaneous injection of $5 \times 10^{6}$ cells in $100 \mu \mathrm{L}$ Matrigel. Cells were implanted in the left or right flank of male athymic nude (nu/nu) mice. The animals had free access to pathogen-free food and acidified water. Potassium sorbate was added to the drinking water to prevent bacterial or fungal contamination. Mice developed tumors sized at least $\sim 100 \mathrm{~mm}^{3}$ within 3 weeks. In vivo studies were conducted using xenograft mice in compliance with the principles and procedures approved by the local Institutional Animal Care and Use Committee. ${ }^{31,32}$

Briefly, mice bearing tumors were randomly divided into four groups $(\mathrm{n}=6)$ : (1) free CUR $(25 \mu \mathrm{g}$ in DMSO); (2) CUR LPs (25 $\mu \mathrm{g}$ CUR equivalent in 
PBS); (3) A15-CUR LPs (25 $\mu \mathrm{g}$ CUR equivalent in PBS); and (4) Blank LPs. All treatments were intravenously applied and the size of tumor was measured with digital vernier caliper. The mice were euthanized after 7 days following treatment. Tumor volume (V) was calculated according to the formula: $\left(\mathrm{W}^{2} \times \mathrm{L}\right) / 2$, in which $\mathrm{W}$ was the widest point of tumor measurement and $\mathrm{L}$ the longest point tumor dimension. Relative tumor volume (R) was calculated by the formula: $\mathrm{V}_{\mathrm{i}} /$ $\mathrm{V}_{0}$, in which $\mathrm{V}_{0}$ was the tumor volume of day 0 and $\mathrm{V}_{\mathrm{i}}$ the volume of tumor at the point of measuring. The antitumor activity was determined by relative tumor inhibitory rate (IR, \%), which could be calculated with the formula $[1-[\mathrm{R}$ (treatment group) $/ \mathrm{R}$ (negative control group)] $] \times 100 \%$.

\section{Tissue Distribution Studies}

Mice bearing tumors (above) were randomly divided into three groups $(n=54):(1)$ free CUR; (2) CUR LPs; and (3) A15-CUR LPs, which were administered in the same dose via the tail vein $(10 \mathrm{mg} / \mathrm{kg})$. At predetermined time points (at $0.5,3,6$, and 12 hrs post i.v. administration), three animals from each group were given anesthesia, and their blood was collected from the postorbital vein and centrifugated to obtain the serum. Tissues of interest (heart, liver, spleen, lung, kidney, and tumor) were collected immediately after rinsed with normal saline and dried with tissue paper. Serum and tissue samples were frozen at $-20^{\circ} \mathrm{C}$ until analysis. After treatment, the mice were sacrificed with their main organs weighed and tissue sections collected.

\section{Statistical Analysis}

All values were presented as mean and standard deviation (mean $\pm \mathrm{SD}$ ), and the significance of differences was investigated using ANOVA or unpaired Student's $t$-test at $\mathrm{p}<0.05$.

\section{Result And Discussion Characterization Of AI5-CUR LPs}

To our knowledge, this study was the first to demonstrate the role of CUR in the stem cells of the prostate, and the drug was considered to be very suitable as a potential new treatment of prostate cancer. The results showed that CUR induced the growth inhibition and apoptosis effects in prostate stem cells in a dose-dependent manner. In this study, phospholipids, cholesterol, and other lipids and CUR were mixed in an organic solvent and rotary evaporated in a vacuum. When a uniform membrane was developed, aqueous buffer was added to make the lipid hydrate into liposomes (Figure 1) in the form of yellow powder. When water was gently added for injection, the powder quickly dispersed and formed yellow semitransparent colloidal suspensions. The results suggested that the average particle size was $86.6 \mathrm{~nm}$, the zeta potential was $-26.2 \mathrm{mV}$, the

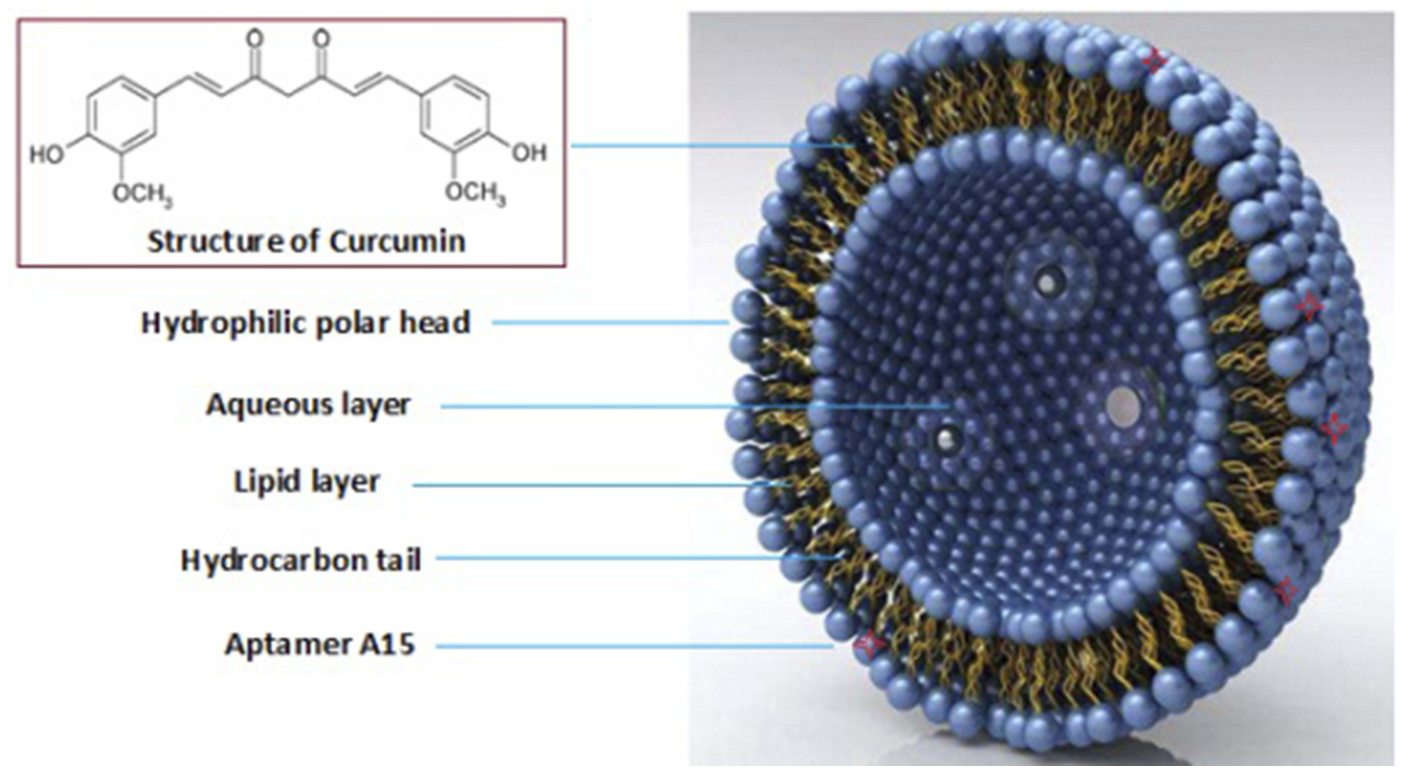

Figure I The basic structure of aptamer AI5 modified CUR liposomes. 
Table I The Characteristics Of Aptamer AI5 Modified CUR LPs $(n=3)$

\begin{tabular}{|l|l|l|}
\hline Parameters & CUR LPs & Al5-CUR LPs \\
\hline Particle size (nm) & $82.8 \pm 6.3$ & $86.6 \pm 4.5$ \\
Drug-loading (\%) & $5.1 \pm 0.3$ & $6.2 \pm 0.4$ \\
Encapsulation efficiency (\%) & $91.6 \pm 1.5$ & $92.3 \pm 1.2$ \\
Polydispersity index & 0.23 & 0.21 \\
Zeta potentials (mV) & $-23.5 \pm 2.9$ & $-26.2 \pm 3.2$ \\
\hline
\end{tabular}

entrapment efficiency was $92.3 \%+1.2 \%$, and the drug loading was $6.2 \%+0.4 \%$. Compared with the conventional injection, there was no significant changes in the indexes of the accelerated test. Therefore, liposomes effectively improved the stability of the drug. In addition, there was no significant change in physical and chemical properties compared with ordinary CUR liposomes (Table 1). The surface morphology of LPs

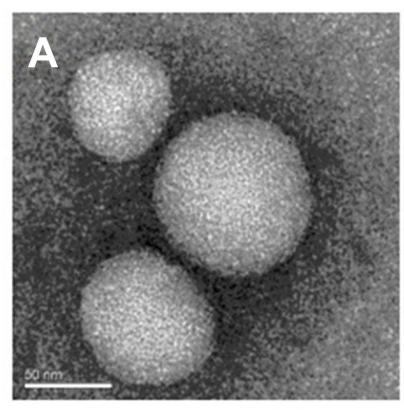

C

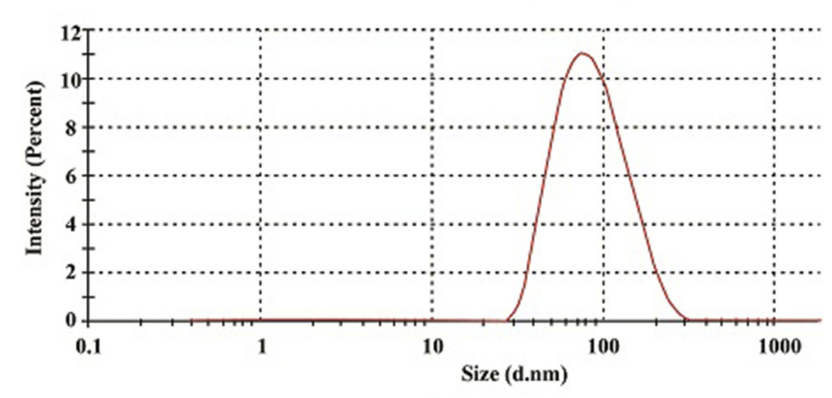

Zeta Potential Distribution

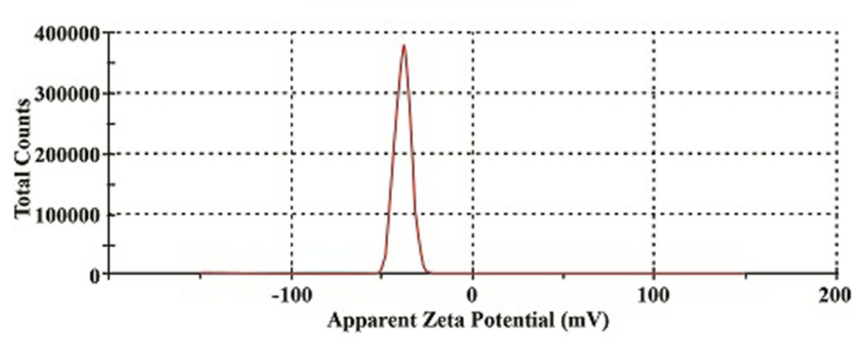

encapsulating CUR, prepared by the thin-film dispersion technique, was studied by TEM. Figure 2 is a TEM scan showing the formation of spherical and smooth LPs. Scanning also showed that the particles had a uniform size distribution and low dispersion, as shown in Table 1.

\section{In Vitro Release}

The release kinetics of CUR from aptamer A15 modified LPs was studied for $48 \mathrm{hrs}$. Drug release from LPs occurred in a biphasic manner, with an initial burst phase followed by a diffusion-controlled drug release phase featured at a slower pace. In our studies, due to the drug desorption and release from the surface of LPs, an initial burst phase (20-25\%) was observed within 2 hrs. As shown in Figure 3, during the entire study period, a sustained CUR release to a total of about $68 \%$ was found. There was no significant difference in
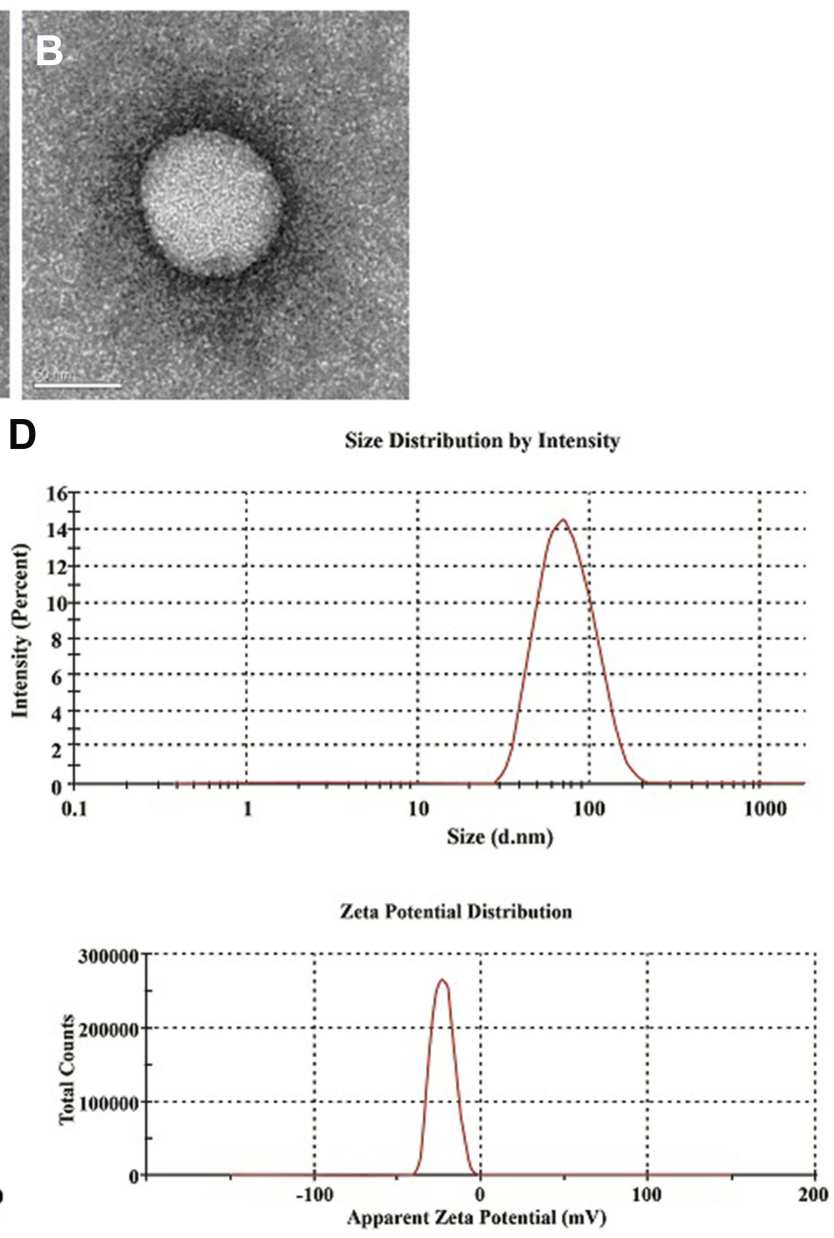

Figure 2 Transmission electron microscopy of aptamer AI 5 modified CUR liposomes. (A) Initial stage. (B) After 3 months of stability observation. Magnification $\times 100,000$. Size and zeta potential distribution (C) AI5-CUR LPs and (D) CUR LPs. 


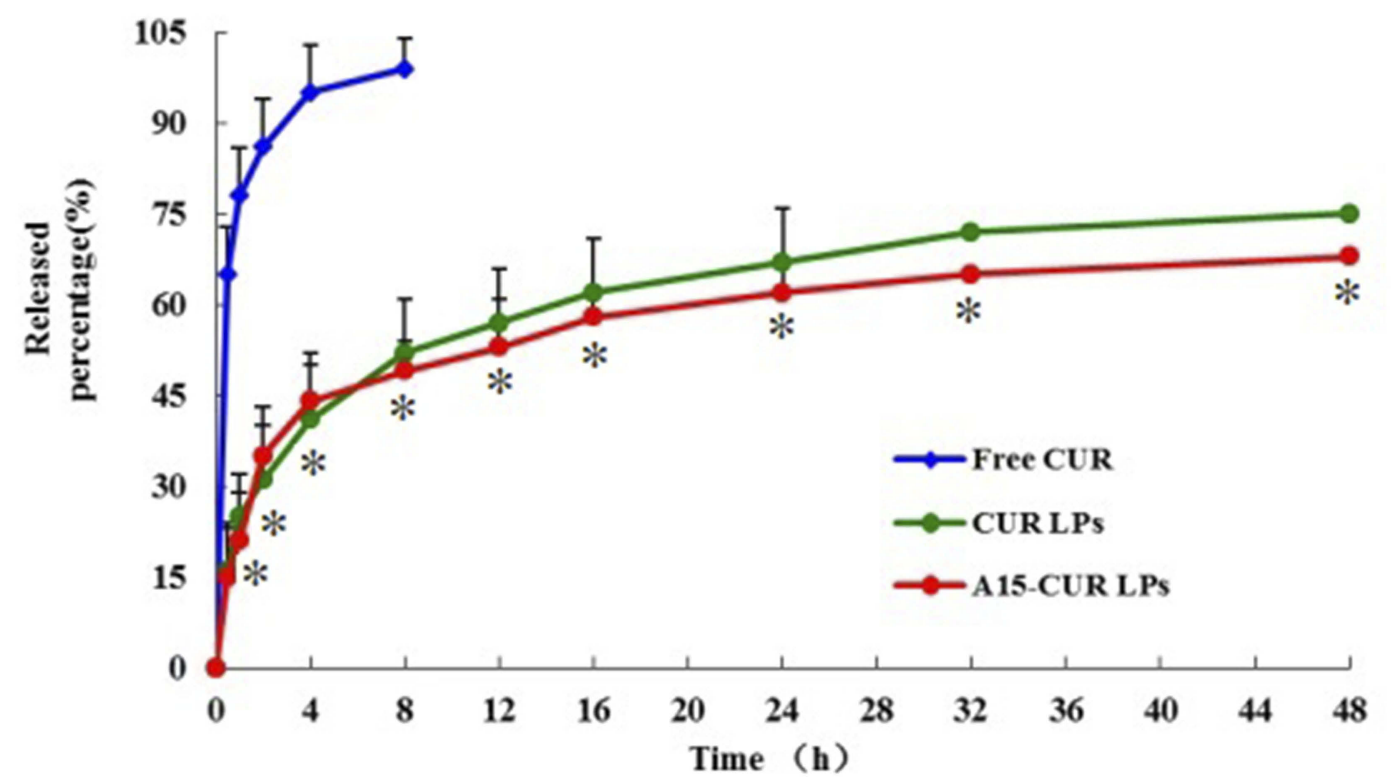

Figure 3 The release profile of free CUR (blue line), CUR LPs (green line), and AI5-CUR LPs (red line) $(n=6) .{ }^{*} p<0.05$, compared with free CUR.

the release behavior of the two kinds of liposomes ( $>$ >0.05). Several models (Higuchi; Weibull; Neibergull; zero-order; first-order) were used to describe drug release from LPs, the best being the Higuchi equation, expressed as $\mathrm{Y}=6.598 \mathrm{~T}_{1 / 2}-1.265, \mathrm{r}=0.9993$, indicating that CUR could be controlled released from the LPs.

\section{Stability}

The stability data of CUR LPs and A15-CUR LPs are summarized in Table 2. In the stability test, LPs maintained a good round shape and the data showed no significant change in A15-CUR LPs. In addition, no aggregation or precipitation of LPs was observed during storage for 3 months. The stability study indicated that a suitable formulation (lyophilized liposomes) increased the storage time of the drug.

Table 2 Physical Stability Of CUR LPs And A I5-CUR LPs At $25^{\circ} \mathrm{C}$ $\pm 2^{\circ} \mathrm{C}$, Relative Humidity $(60 \% \pm 5 \%)(n=3)$

\begin{tabular}{|c|c|c|c|c|}
\hline & \multicolumn{2}{|l|}{ CUR LPs } & \multicolumn{2}{|c|}{ Al5-CUR LPs } \\
\hline & 0 Day & $\begin{array}{l}\text { 3rd } \\
\text { Month }\end{array}$ & 0 Day & $\begin{array}{l}\text { 3rd } \\
\text { Month }\end{array}$ \\
\hline Particle size $(\mathrm{nm})$ & $82.8 \pm 6.3$ & $83.4 \pm 5.1$ & $86.6 \pm 4.5$ & $84.7 \pm 2.9$ \\
\hline $\begin{array}{l}\text { Zeta potential } \\
(\mathrm{mV})\end{array}$ & $-23.5 \pm 2.9$ & $-22.6 \pm 1.5$ & $-26.2 \pm 3.2$ & $-23.4 \pm 1.4$ \\
\hline DL (\%) & $5.1 \pm 0.3$ & $4.8 \pm 0.5$ & $6.2 \pm 0.4$ & $5.8 \pm 0.3$ \\
\hline ER (\%) & $91.6 \pm 1.5$ & $89.4 \pm 1.3$ & $92.3 \pm 1.2$ & $89.8 \pm 1.5$ \\
\hline
\end{tabular}

\section{Hemolysis Testing}

Hemolysis study was conducted to study the potential toxicity after the intravenous injection of free CUR, CUR LPs, and A15-CUR LPs in vivo. The leakage of hemoglobin was used to quantitatively compare the membrane-damaging properties of test formulations. The results suggested that free CUR showed much higher hemolysis rate than CUR LPs and A15-CUR LPs $(10.8 \%$ vs $4.6 \% / 3.9 \%, p>0.05)$. But there was no significant difference between the two LPs. Therefore, the aptamer A15-modified liposome was a safe formulation for injection.

\section{Cell Viability}

To evaluate the differential effects of free CUR, blank LPs, CUR LPs, and A15-CUR LPs on cell viability, a CCK-8 assay for viability was utilized. Cellular viability of different formulations during incubation is shown in Figure 4. Even after incubation for $48 \mathrm{hrs}$ with $20 \mathrm{mM}$ blank LPs, the cellular viability was above $80 \%$. This result showed that blank LPs had lower cellular cytotoxicity. By contrast, under the same incubation condition (concentration), the cellular cytotoxicity of CUR LPs increased significantly, which might be caused by the increase of intracellular drug concentration through the transportation of liposomes. In addition, at the same concentration, the two LPs of CUR (with or without A15 modified) exhibited a similar trend of cellular 


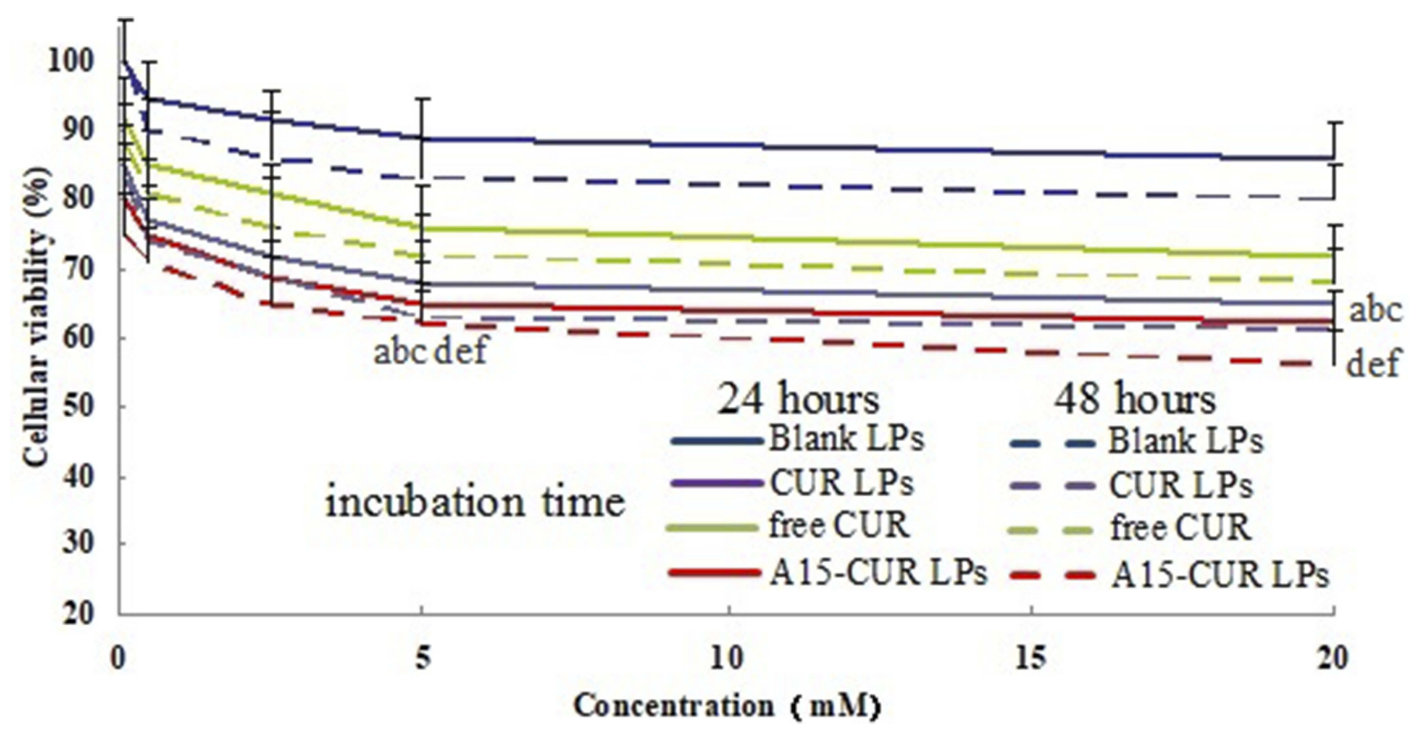

Figure 4 The cellular viability of DUI 45 cells cultured with free CUR, blank LPs, CUR LPs, and AI5-CUR LPs in the incubation time of 24 or 48 hrs at the 5 different concentrations $(n=6)$. Data $=$ mean \pm SD. At 24 hrs: ${ }^{a} p<0.05$, compared with blank LPs; ${ }^{b} p<0.05$, compared with free CUR; ${ }^{c} p<0.05$, compared with CUR LPs. At 48 hrs: ${ }_{\mathrm{P}}^{\mathrm{d}}<0.05$, compared with blank LPs; ${ }^{\mathrm{e}} \mathrm{P}<0.05$, compared with free CUR; ${ }_{\mathrm{p}}^{\mathrm{p}}<0.05$, compared with CUR LPs.

cytotoxicity. With the extension of incubation time, A15-CUR LPs showed a greater inhibitory effect on cells.

\section{Cellular Internalization}

The cellular internalization of free CUR, CUR LPs, and A15-CUR LPs in DU145 cells was observed by confocal microscopy. As shown in Figure 5, a strong green fluorescence was observed in the cytoplasmic region after the incubation of A15-CUR LPs for $2 \mathrm{hrs}$. Cell internalization in DU145 cells was higher for A15-CUR LPs than others. The results showed that surface modification enabled cells to internalize and more drugs to enter cells successfully. In quantitative cell uptake studies, coumarin- 6 on the three formulations was quantified by recovering drug LPs from cells and measuring their
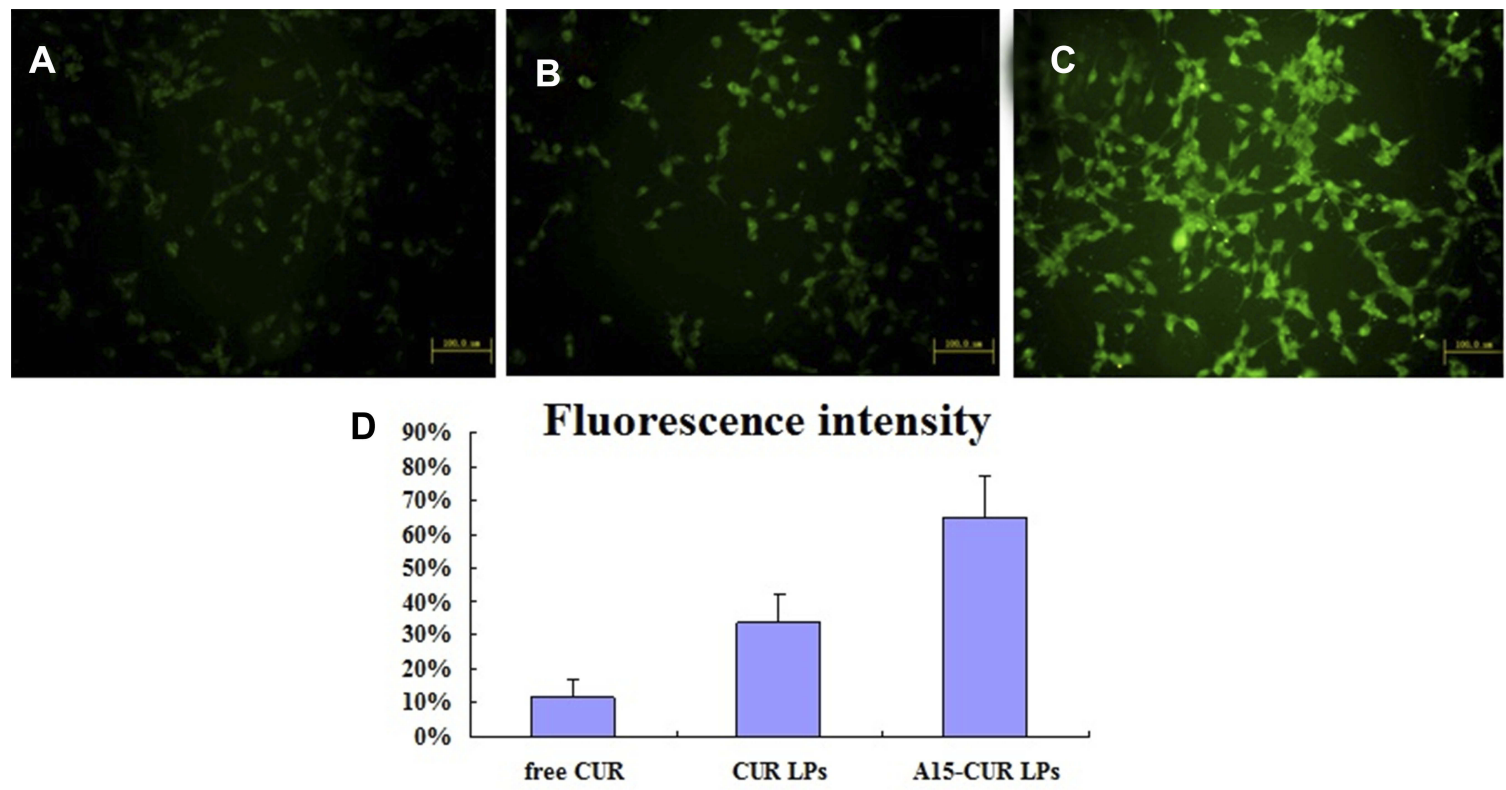

Figure 5 Confocal images of cellular uptake of free CUR (A), CUR LPs (B), and AI5-CUR LPs (C) by DUI 45 cells. Incubation time was 2 hrs. (D) Fluorescence intensity of the three groups. 


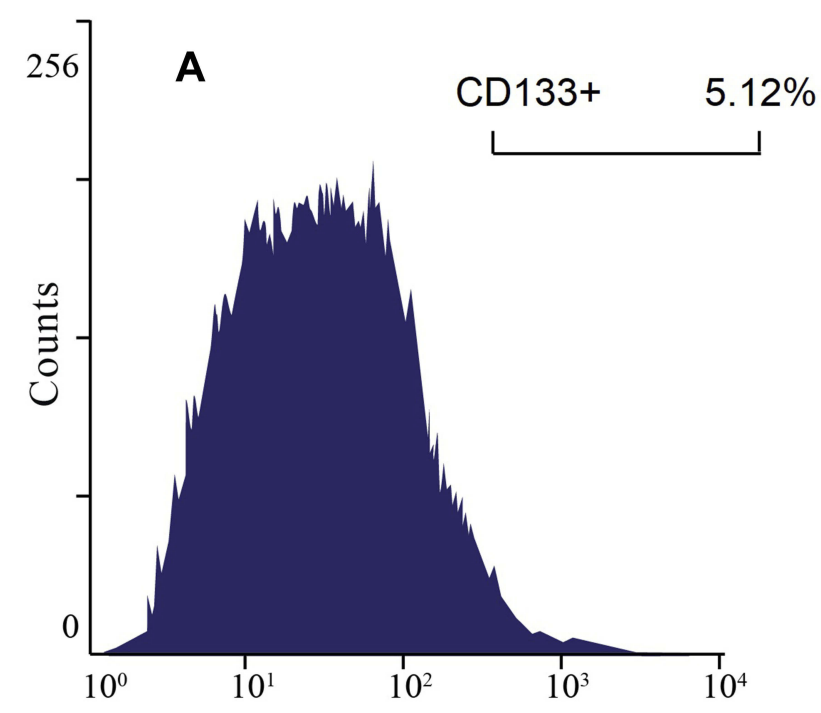

CD133-PE

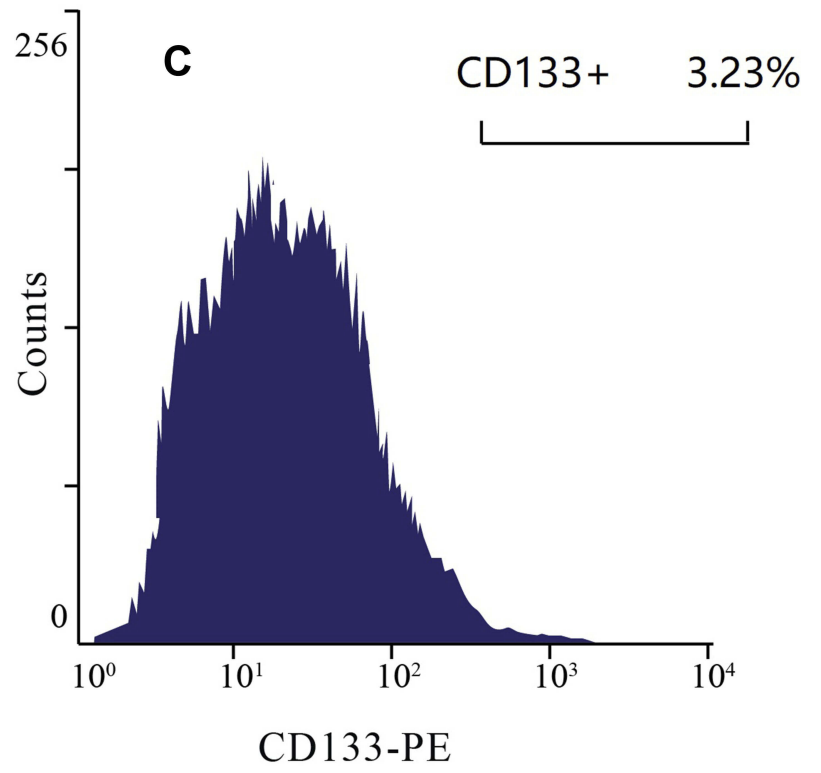

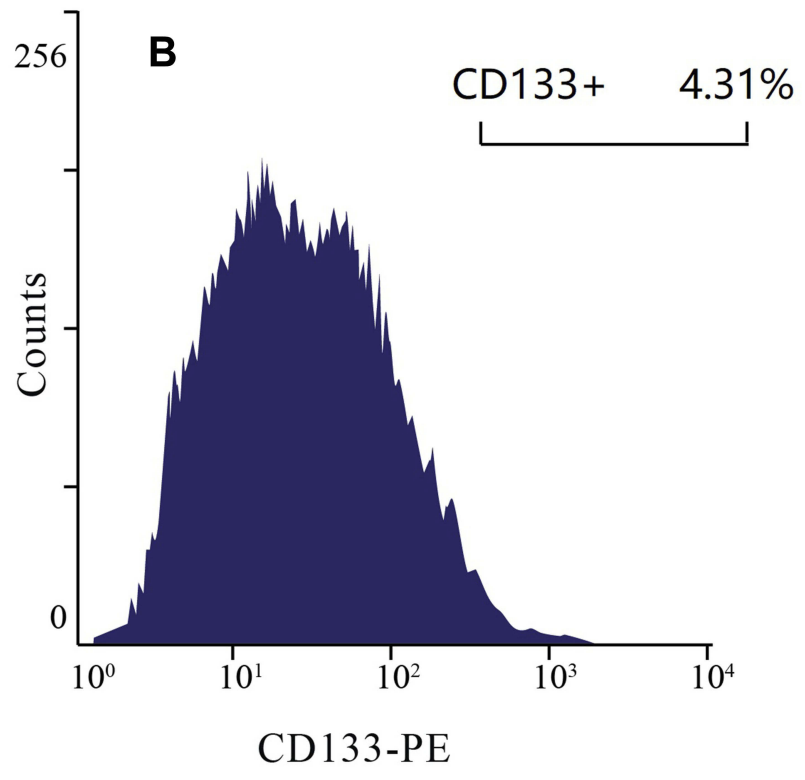

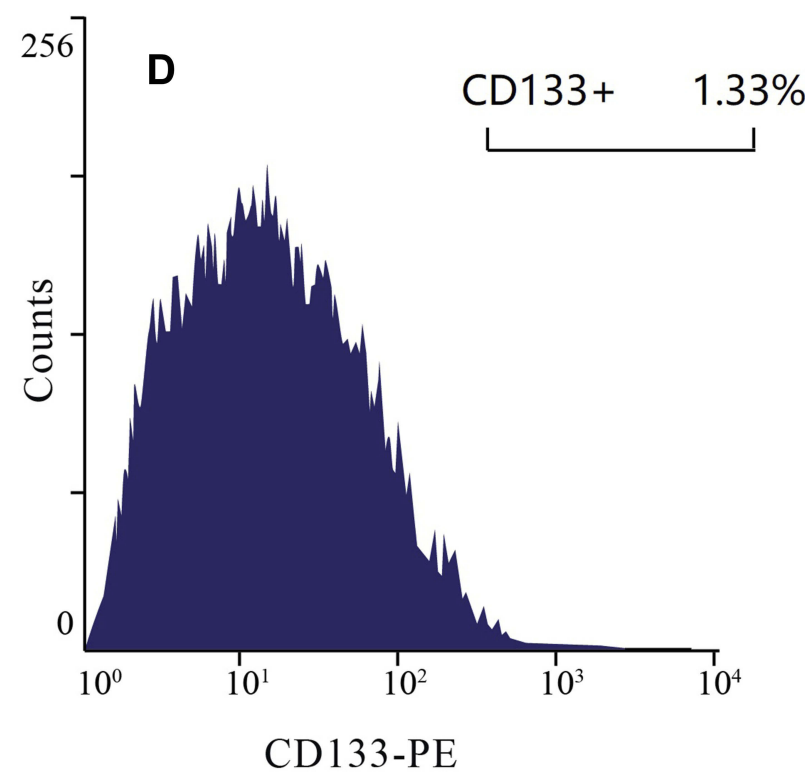

Figure 6 Flow cytometry analysis of the CDI33+ population. The CDI33+ population in DUI 45 cells was analyzed by flow cytometry with PE-CDI33+ antibody. (A) $5.12 \%$ CDI33+ cells were detected among untreated DUI45 cells. (B) $4.31 \%$ CDI33+ cells were detected in free CUR treated cells. (C) $3.23 \%$ CDI33+ cells were detected in DUI45 cells treated with CUR LPs. (D) $1.33 \%$ CDI33+ cells were detected in DUI45 cells treated with AI5-CUR LPs.

fluorescence (normalization to the total cell protein content per milligram). Mean fluorescence intensities (Figure 5D) for A15-CUR LPs were approximately 2-folds higher than those for CUR LPs. The uptake of A15-CUR LPs potentially involved specific interactions of the A15 group with its receptor. Hence, the overexpression of CD133+ on DU145 cells could promote cellular entry of liposomes with the A15 modification.

In the study of flow cytometry assays, an average of $5.12 \%$ CD133 + cells were detected in untreated DU145 cells and the CD133+ population was reduced to $4.31 \%$ and 3.23\% with free CUR and CUR LPs treatment, respectively. However, when CUR LPs were modified with A15, the $\mathrm{CD} 133+$ population was markedly reduced to $1.33 \%$ (Figure 6).

\section{Tumor Targeting}

The tumor-targeting efficiency of DiD fluorescence-labeled A15-CUR LPs in mice bearing s.c. DU145 cancer xenograft was monitored by non-invasive fluorescence optical imaging. Equivalent amounts of DiD-CUR, DiD-CUR LPs, and DiD-A15-CUR LPs were injected into mice through 
$\max { }_{m}$ min
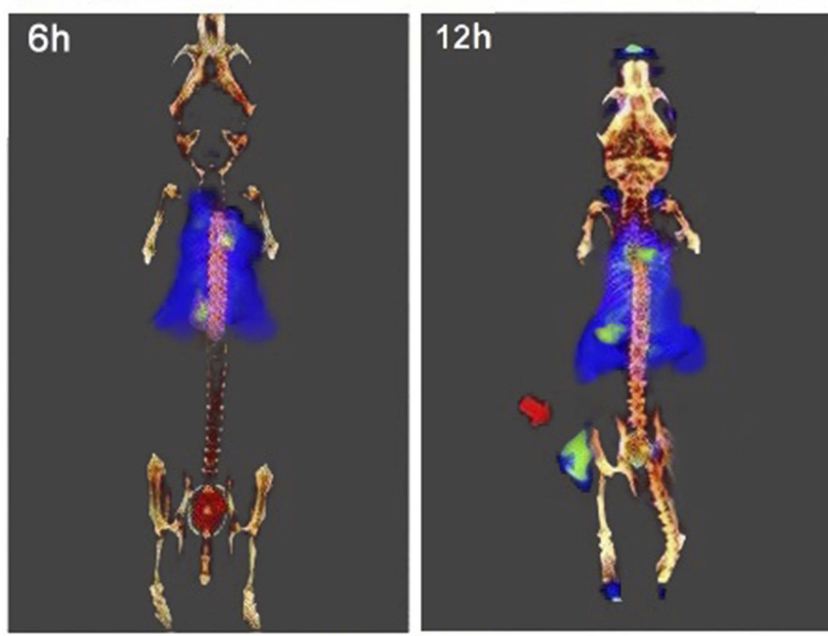

Free CUR

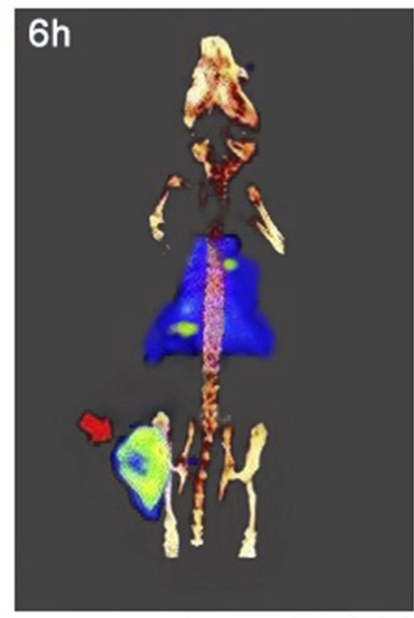

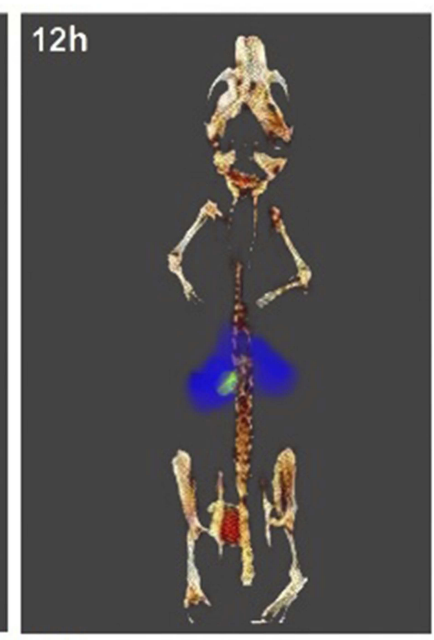

CUR LPS
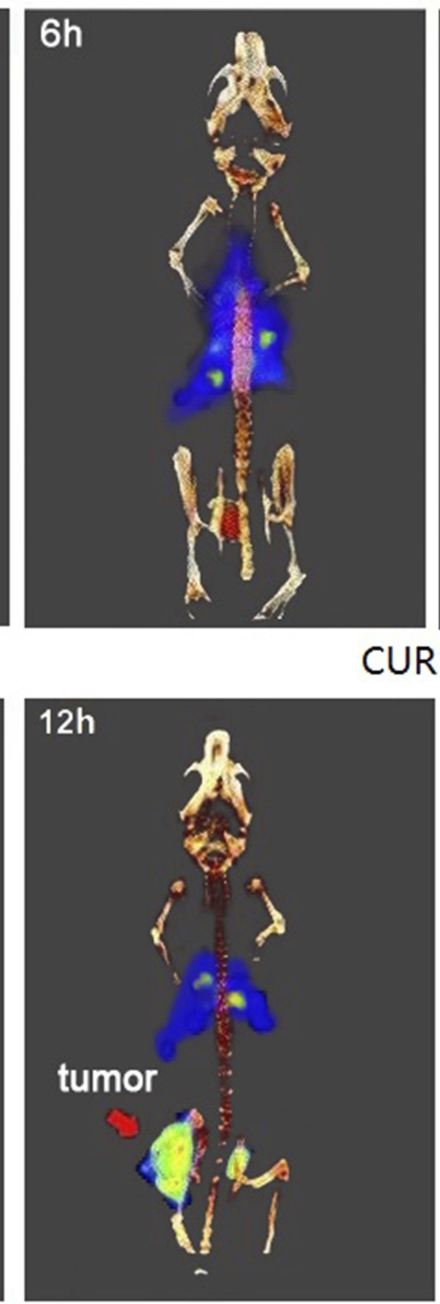

A15-CUR LPS

Figure 7 Fluorescence images of subcutaneous DUI 45 tumor-bearing nude mice after intravenous injection of free CUR, CUR LPs and AI5-CUR LPs, 6 h and I2 h after injection.

the tail vein. The entire animal became fluorescent immediately after liposome administration, and substantial contrast between subcutaneous tumor and normal tissue was observed from 0 to $12 \mathrm{hrs}$ (Figure 7). According to the imaging results, the uptake of DiD-A15-CUR LPs in tumors increased gradually compared to normal tissue following injection, peaking at $6 \mathrm{hrs}$, and maintaining a strong fluorescence signal for $12 \mathrm{hrs}$. This suggested that DiD-A15-CUR LPs were more likely to accumulate in tumors preferentially than normal tissues, which may be due to prolonged circulation and enhanced permeability and retention (EPR) effects. Compared with the DiD-A15-CUR LPs group, DiD-CUR and DiD-CUR LPs had faint fluorescence intensity in tumor of mice at any time, indicating that ordinary LPs and drugs had weak tumor-targeting function.

\section{In Vivo Evaluation}

A problem with the current treatment of prostate cancer was that although chemotherapeutic drugs killed the majority of cancer cells, the cancer stem cells could still lead to drug resistance and tumor recurrence. Therefore, in this study, we designed A15 modified CUR LPs for prostate cancer CSCs. As shown in Figure 8, compared with the control group, both LPs groups resulted in growth inhibition of DU145 cells transplanted solid tumors and the obvious decrease of tumor size. Compared with blank LPs, the volume of tumor treated with A15 CUR-LPs decreased significantly, while that of animals treated with CUR-LPs and free CUR decreased not as much. The average weight and volume of the tumor are provided in Table 3. The appearance of the tumors was in agreement 


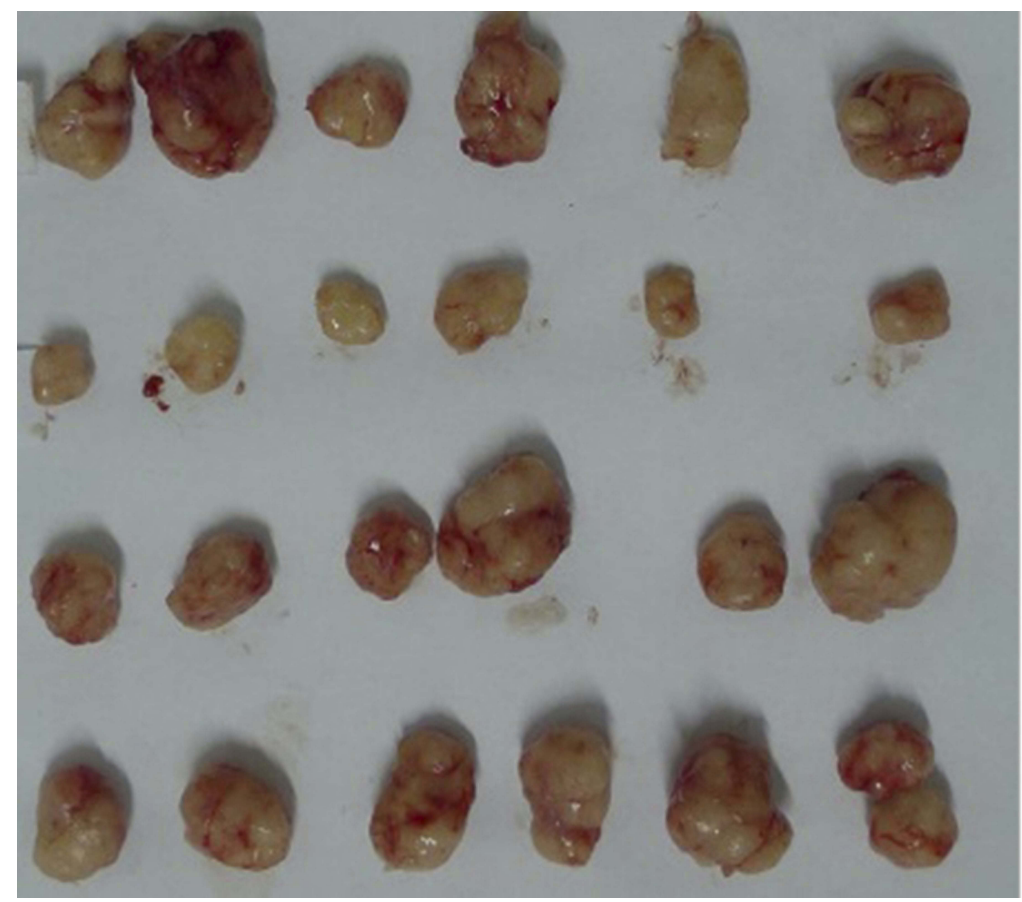

blank LPs

A15-CUR LPs

CUR LPs

free CUR

Figure 8 Changes of tumor volume in nude mice transplanted with human adenocarcinoma cell line DUI45 on 7th day.

with the statistical analysis of the tumor volume data, which showed that compared with the control group, all the treatment groups significantly inhibited the growth of tumor volume $(\mathrm{P}<0.05)$, with the A15-CUR LPs group showing the highest effectiveness. All the results indicated that A15-CUR LPs had better antitumor effect in vivo than unmodified liposomes. Pathological studies showed that there were no obvious pathological changes in the tissues of the treatment groups (data not shown).

\section{Biodistribution Studies}

Figure 9 presents the mean concentration-time profiles of CUR in a unit mass of each mice organ. Drug concentration in tissues indicated that A15-CUR LPs could deliver CUR mainly to tumor after intravenous administration. The concentration of CUR in tumor was significantly higher than that in other tissues and the plasma. The total amount of drug accumulated in each organ within $24 \mathrm{hrs}(\mathrm{AUC} 0-\mathrm{t})$ was calculated, and the results are shown in Table 4. The classical Gupta method was usually used to evaluate the targeting efficiency (Target Index, TI). As shown in Table 4, A15CUR LPs had higher AUC inside tumor and the spleen than the injection group. TI was 3.12 and 1.12, but there was no significant difference in the increase of the spleen. The reasons could be that both mediated

Table 3 The Effect Of Free CUR, CUR LPs, Or AI5-CUR LPs On Nude Mice Of DUI45 Cells

\begin{tabular}{|c|c|c|c|c|c|}
\hline \multirow[t]{2}{*}{ Formulation } & \multicolumn{2}{|c|}{$\operatorname{TV}\left(\mathrm{mm}^{3}\right)$} & \multirow[t]{2}{*}{ Tumor Weight (g) } & \multirow[t]{2}{*}{$\mathbf{R}$} & \multirow{2}{*}{$\begin{array}{l}\text { IR } \\
\text { (\%) }\end{array}$} \\
\hline & $d_{l}$ & $d_{10}$ & & & \\
\hline Blank LPs & $129 \pm 26$ & $659 \pm 136$ & $0.625 \pm 0.167$ & $5.11 \pm 1.39$ & \\
\hline Free CUR & $|3| \pm 22$ & $365 \pm 156^{\mathrm{a}}$ & $0.325 \pm 0.119^{\mathrm{a}}$ & $2.79 \pm 1.13^{\mathrm{a}}$ & $45.4 \%$ \\
\hline CUR LPs & $126 \pm 28$ & $275 \pm 135^{\mathrm{ab}}$ & $0.219 \pm 0.107^{\mathrm{ab}}$ & $2.18 \pm 0.95^{\mathrm{ab}}$ & $57.3 \%$ \\
\hline AI5-CUR LPs & $|3| \pm 3 \mid$ & $121 \pm 72^{\mathrm{abc}}$ & $0.116 \pm 0.049^{\mathrm{abc}}$ & $0.92 \pm 0.39^{\mathrm{abc}}$ & $82.0 \%$ \\
\hline
\end{tabular}

Notes: ${ }^{\mathrm{a}} \mathrm{P}<0.05$, compared with blank LPs; ${ }^{\mathrm{b}} \mathrm{P}<0.05$, compared with free CUR; ${ }^{\mathrm{c}} \mathrm{P}<0.05$, compared with CUR LPs.

Abbreviations: TV, tumor volume; R, relative tumor volume. 


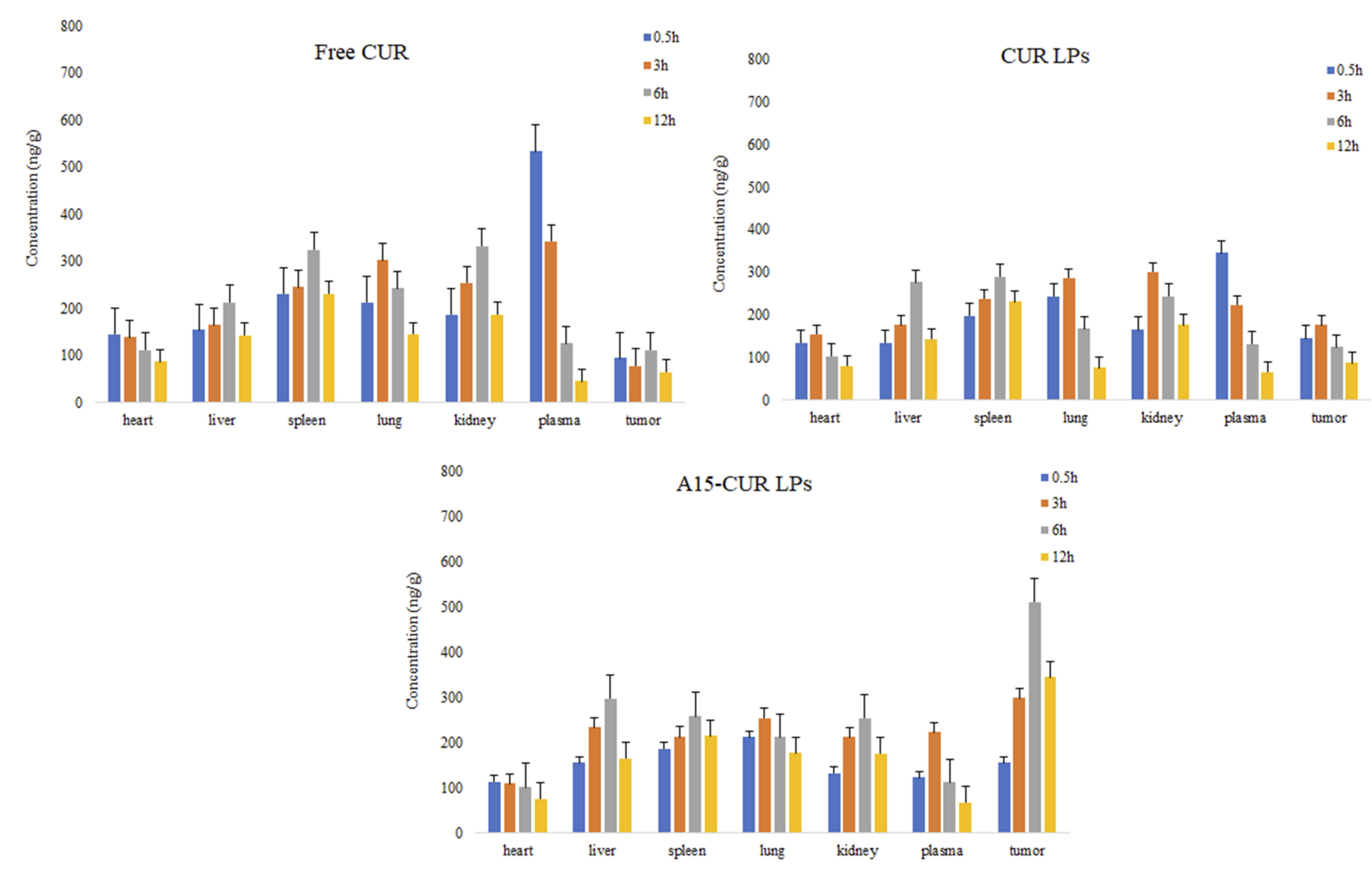

Figure 9 The research results of tissue distribution.

Table 4 The $A_{U C}{ }_{0-12 h}$ Of CUR In Plasma And Tissues After I.V. Administration Of Injection And Liposomes To Mice ( $\left.n=6\right)$

\begin{tabular}{|l|l|l|l|l|l|l|l|}
\hline Formulation & Heart & Liver & Spleen & Lung & Kidney & Plasma & Tumor \\
\hline Free CUR (ng h/g) & 1328.5 & 2031.0 & 3113.5 & 2625.3 & 2987.3 & 2305.5 & $1032.3 *$ \\
CUR LPs (ng h/g) & 1291.5 & 2322.5 & 2894.3 & 2072.5 & 2655.5 & 1833.5 & $1484.3 *$ \\
AI5-CUR LPs (ng h/g) & 1126.3 & 2674.5 & 2630.0 & 2449.8 & 2419.0 & 1475.0 & 4356.3 \\
Ratio $^{\mathrm{a}}$ & 0.8 & 1.3 & 0.8 & 0.9 & 0.8 & 0.6 & 4.2 \\
Ratio $^{\mathrm{b}}$ & 0.9 & 1.2 & 0.9 & 1.2 & 0.9 & 0.8 & 2.9 \\
\hline
\end{tabular}

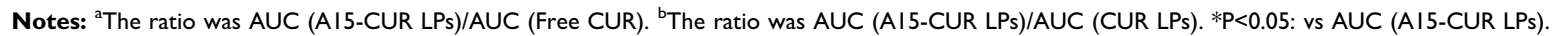

receptors and the reticuloendothelial system (RES) were in the spleen. As a result, drugs are more easily distributed to these organs.

\section{Acknowledgment}

Tao Wei and Zhou Yanling are co-corresponding authors.

\section{Disclosure}

The authors report no conflicts of interest in this work.

\section{References}

1. Qu M, Ren SC, Sun YH. Current early diagnostic biomarkers of prostate cancer. Asian J Androl. 2014;16(4):549-554. doi:10.4103/ 1008-682X.129211
2. Sowery RD, So AI, Gleave ME. Therapeutic options in advanced prostate cancer: present and future. Curr Urol Rep. 2007;8(1):53-59. doi:10.1007/s11934-007-0021-9

3. Wang L, Ma L, Wang X, Li B, Guo S, Qiao Q. Association of serum EPCA-2 level with prostate cancer in Chinese Han population. Int $J$ Clin Exp Pathol. 2015;8(8):9397-9403.

4. Yang L, Xie S, Feng X, et al. Worldwide prevalence of human papillomavirus and relative risk of prostate cancer: a meta-analysis. Sci Rep. 2015;5:14667. doi:10.1038/srep14667

5. Tan HL, Thomas-Ahner JM, Grainger EM, et al. Tomato-based food products for prostate cancer prevention: what have we learned? Cancer Metastasis Rev. 2010;29(3):553-568. doi:10.1007/s10555010-9246-z

6. Brenton J, Baguley KA, Bolam ORL, Skinner TL. The effect of nutrition therapy and exercise on cancer-related fatigue and quality of life in men with prostate cancer: a systematic review. Nutrients. 2017;9(9):1003. doi:10.3390/nu9091003

7. Sinha R, Anderson DE, McDonald SS, Greenwald P. Cancer risk and diet in India. $J$ Postgrad Med. 2003;49(3):222-228. 
8. Stan SD, Singh SV, Brand RE. Chemoprevention strategies for pancreatic cancer. Nat Rev Gastroenterol Hepatol. 2010;7(6):347-356. doi:10.1038/nrgastro.2010.61

9. Cimino S, Sortino G, Favilla V, et al. Polyphenols: key issues involved in chemoprevention of prostate cancer. Oxid Med Cell Longev. 2012;2012:632959. doi:10.1155/2012/632959

10. Aggarwal BB. Prostate cancer and curcumin: add spice to your life. Cancer Biol Ther. 2008;7(9):1436-1440. doi:10.4161/cbt.7.9.6659

11. Shishodia S, Sethi G, Aggarwal BB. Curcumin: getting back to the roots. Ann N Y Acad Sci. 2005;1056:206-217. doi:10.1196/annals. 1352.010

12. Maheshwari RK, Singh AK, Gaddipati J, et al. Multiple biological activities of 18rcumin: a short review. Life Sci. 2006;78(18):20812087. doi:10.1016/j.1fs.2005.12.007

13. Wang Z, Zhang Y, Banerjee S, Sarkar FH. Notch-1 down-regulation by curcumin is associated with the inhibition of cell growth and the induction of apoptosis in pancreatic cancer cells. Cancer. 2006;106 (11):2503-2513. doi:10.1002/cncr.21904

14. Sa G, Das T. Anticancer effects of curcumin: cycle of life and death. Cell Div. 2008;3:14. doi:10.1186/1747-1028-3-14

15. Adahoun MA, A-Akhras MH, Jaafar MS, Bououdina M. Enhanced anti-cancer and antimicrobial activities of curcumin nanoparticles. Artif Cells Nanomed Biotechnol. 2017;45(1):98-107. doi:10.3109/ 21691401.2015.1129628

16. Kreso A, Dick JE. Evolution of the cancer stem cell model. Cell Stem Cell. 2014;14(3):275291. doi:10.1016/j.stem.2014.02.006

17. La Porta CA. Mechanism of drug sensitivity and resistance in melanoma. Curr Cancer Drug Targets. 2009;9(3):391397. doi:10.2174/ 156800909788166574

18. Goksel G, Bilir A, Uslu R, Akbulut H, Guven U, Oktem G. WNT1 gene expression alters in heterogeneous population of prostate cancer cells; decreased expression pattern observed in CD133+/CD44+ prostate cancer stem cell spheroids. J BUON. 2014;19(1):207-214.

19. Islami M, Mortazavi Y, Soleimani M, Nadri S. In vitro expansion of CD 133+ cells derived from umbilical cord blood in poly-L-lactic acid (PLLA) scaffold coated with fibronectin and collagen. Artif Cells Nanomed Biotechnol. 2017;6:1-9.

20. Li S, Wang XP. In vitro and in vivo evaluation of novel NGRmodified liposomes containing brucine. Int $J$ Nanomedicine. 2017;12:5797-5804. doi:10.2147/IJN.S136378

21. Keefe AD, Pai S, Ellington A. Aptamers as therapeutics. Nat Rev Drug Discov. 2010;9(7):537-550. doi:10.1038/nrd3141
22. Shigdar S, Qiao L, Zhou SF, et al. RNA aptamers targeting cancer stem cell marker CD133. Cancer Lett. 2013;330(1):84-95. doi:10. 1016/j.canlet.2012.11.032

23. Ma J, Zhuang H, Zhuang Z. et al. Development of docetaxel liposome surface modified with CD133 aptamers for lung cancer targeting. Artif Cells Nanomed Biotechnol;2017. 1-8. doi:10.1080/21691401.2017. 1394874

24. Gao J, Liu W, Xia Y, et al. The promotion of siRNA delivery to breast cancer overexpressing epidermal growth factor receptor through antiEGFR antibody conjugation by immunoliposomes. Biomaterials. 2011;32(13):3459-3470. doi:10.1016/j.biomaterials.2011.01.034

25. Gao J, Sun J, Li H, et al. Lyophilized HER2-specific PEGylated immunoliposomes for active siRNA gene silencing. Biomaterials. 2010;31(9):2655-2664. doi:10.1016/j.biomaterials.2009.11.112

26. Shi B, Fang C, You MX. Stealth MePEG-PCL micelles: effects of polymer composition on micelle physicochemical characteristics, in vitro drug release, in vivo pharmacokinetics in rats and biodistribution in S180 tumor bearing mice. Colloid Polym Sci. 2005;283:954967. doi:10.1007/s00396-004-1243-8

27. Zu YG, Meng L, Zhao XH, et al. Preparation of 10-hydroxycamptothecin-loaded glycyrrhizic acid-conjugated bovine serum albumin nanoparticles for hepatocellular carcinoma-targeted drug delivery. Int J Nanomedicine. 2013;8:1207-1222. doi:10.2147/IJN.S40493

28. Lian H, Sun J, Yu YP, et al. Supramolecular micellar nanoaggregates based on a novel chitosan/vitamin E succinate copolymer for paclitaxel selective delivery. Int J Nanomedicine. 2011;6:3323-3334. doi:10.2147/IJN.S26305

29. Ray S, Ghosh Ray S, Mandal S. Development of bicalutamide-loaded PLGA nanoparticles: preparation, characterization and in-vitro evaluation for the treatment of prostate cancer. Artif Cells Nanomed Biotechnol. 2017;45(5):944-954. doi:10.1080/21691401.2016.1196457

30. Yang JP, Liu Y, Zhong W, et al. Chemoresistance of CD133+ cancer stem cells in laryngeal carcinoma. Chin Med J (Engl). 2011;124:10551060 .

31. Celia C, Calvagno MG, Paolino D, et al. Improved in vitro antitumoral activity, intracellular uptake and apoptotic induction of gemcitabine-loaded pegylated unilamellar liposomes. J Nanosci Nanotechnol. 2008;8(4):2012-2013. doi:10.1166/jnn.2008.065

32. Dong X, Zou S, Guo C, et al. Multifunctional redox-responsive and CD44 receptor targeting polymer-drug nanomedicine based curcumin and alendronate: synthesis, characterization and in vitro evaluation. Artif Cells Nanomed Biotechnol. 2017;1-10.
Publish your work in this journal

Drug Design, Development and Therapy is an international, peerreviewed open-access journal that spans the spectrum of drug design and development through to clinical applications. Clinical outcomes, patient safety, and programs for the development and effective, safe, and sustained use of medicines are a feature of the journal, which has also been accepted for indexing on PubMed Central. The manuscript management system is completely online and includes a very quick and fair peer-review system, which is all easy to use. Visit http://www. dovepress.com/testimonials.php to read real quotes from published authors. 